\title{
Natalidade e revolução em Hannah Arendt
}

\section{Natality and revolution in Hannah Arendt}

DOI: $10.20873 / r p v 6 n 2-04$

\section{Antônio Batista Fernandes}

Orcid: 0000-0002-8968-3754

Email: tonybfprof@gmail.com

\begin{abstract}
Resumo
O presente artigo tem por objetivo discutir o conceito de natalidade e sua relação com o fenômeno revolucionário a partir do pensamento de Hannah Arendt. Para tanto, laçaremos mão de algumas obras de referência da autora para pensar tal categoria, a saber: Origens do Totalitarismo (1951), A condição humana (1951) e Sobre a Revolução (1963). Para Arendt, o conceito de natalidade está diretamente relacionado a capacidade dos indivíduos de iniciarem coisas novas no mundo, isto é, de serem iniciadores de um mundo inteiramente novo. $\mathrm{O}$ fenômeno revolucionário moderno, por sua vez, representa um novus ardo saeclorum, uma novidade que se tornou possível por meio da ação conjunta dos homens e da capacidade de começar própria daqueles que são os recém-chegados ao mundo. Portanto, nosso problema consiste em constatar a centralidade do conceito de natalidade no pensamento político de Arendt, bem como sua relação com o fenômeno revolucionário moderno.
\end{abstract}

\section{Palavras-chave}

Hannah Arendt. Natalidade. Política. Revolução.

\begin{abstract}
This essay aims to examine the concept of natality and its connection with the revolutionary phenomenon from the perspective of Hannah Arendt. For this purpose, it uses some of the author's reference works to understand such category, namely: Origins of Totalitarianism (1951), The Human Condition (1951) and On Revolution (1963). To Arendt, the concept of natality is directly connected to the ability of individuals to initiate new things in the world, that is, to be initiators of an entirely new world. The modern revolutionary phenomenon, in turn, represents a novus ardo saeclorum, a novelty made possible through the joint action of men and the ability to start that is characteristic of those who are newcomers to the world. Therefore, our issue consists in analyzing the centrality of the concept of natality in Arendt's political thought, as well as, its connection with the modern revolutionary phenomenon.
\end{abstract}




\section{Keywords}

Hannah Arendt. Natality. Politics. Revolution.

\section{Introdução}

A categoria da natalidade ocupa um lugar privilegiado na obra de Hannah Arendt, constituindo-se como um conceito central no entendimento de seu pensamento político. Assim sendo, defendemos que tal categoria precisa ser compreendia, inicialmente, à luz do fenômeno revolucionário, pois se encontra profundamente arraigada no contexto de surgimento das principais revoluções modernas, enquanto acontecimentos que tornaram possível o aparecimento da novidade na política, uma espécie de segundo nascimento, manifesto por meio da liberdade e da capacidade de ação política comum aos principais atores das revoluções setecentistas.

A natalidade, que expressa a capacidade de começo inerente a todo indivíduo, pode apontar também para experiências que não são propriamente do âmbito do político, como a emergência do fenômeno totalitário no século XX, que configura um momento de perversão da natalidade política e eliminação de toda espontaneidade humana, conforme atesta Bowen-Moore, ao afirmar que tal fenômeno implica um momento de "negação forçada da liberdade humana, enquanto a capacidade de exibir a identidade distintiva de uma pessoa em ação e discurso [...] sua experiência é a antítese da natalidade política" (1989, p. 45).

Aqui, nos interessa o fato de que existe uma relação estreita entre a categoria arendtiana de natalidade e a experiência revolucionária moderna do novo início, o páthos da novidade protagonizados pelos homens das duas principais revoluções do século XVIII. É o fenômeno revolucionário que testemunha, de maneira inédita na modernidade, "a experiência da natalidade como uma reafirmação do político e uma confirmação da realidade do mundo público comum" (BOWEN-MOORE, 1989, p. 135), são essas experiências que resgatam o espaço para a ação política, que se encontrava esquecido, e atualizam a promessa dos novos começos de que cada homem é capaz por meio de suas ações, palavras e atos, pois, como lembra Arendt, "é com 
palavras e atos que nos inserimos no mundo humano, e essa inserção é como um segundo nascimento" (2016, p. 219).

Na trilha da relação entre natalidade e revolução, buscaremos elucidar neste artigo, à luz do pensamento arendtiano, algumas das principais características da categoria de natalidade política, bem como, a centralidade dessa categoria para a compreensão do fenômeno revolucionário moderno, tendo como referência o páthos do novo início que fez eclodir a experiência revolucionária moderna. O conceito de natalidade (natality) constitui, portanto, uma ideia chave para se pensar a política em Hannah Arendt; não por acaso, nossa autora recorre a essa categoria em muitas de suas obras ${ }^{1}$, sempre com o propósito de afirmar a imensa capacidade humana de iniciar coisas novas a partir da existência de um mundo comum e compartilhado, isto é, de um mundo propriamente político ${ }^{2}$, condição sine qua non da natalidade. Entendemos que a categoria da natalidade em Arendt, encontra-se também diretamente vinculado a outras categorias utilizados por nossa autora em suas obras, tais como: pluralidade, liberdade, ação, promessa, amor mundi e espaço público.

\section{Natalidade e Revolução: a experiência dos novos inícios}

Em sua tese de doutorado intitulada O conceito de amor em Santo Agostinho (1928), Hannah Arendt já havia relacionado a categoria da natalidade com a ideia de amor mundi discutida no texto ${ }^{3}$, porém, foi no fial da obra Origens do Totalitarismo (1951) - precisamente no capítulo intitulado Ideologia e terror, e com referência à célebre passagem de Santo Agostinho em De

\footnotetext{
${ }^{1}$ Dentre as obras em que Arendt aborda direta ou indiretamente o conceito de natalidade e a ideia de novo início ou de novo começo, podemos citar: The Origens of Totalitarism (1951); The condition human (1958); Between past and future (1961); On revolution (1963); Crises of the Repúblic (1969).

2 Nesse sentido, Bowen-Moore esclarece que "o nascimento na ordem política é uma prerrogativa da natalidade pela qual o iniciante começa uma ação no mundo público dos assuntos humanos [...] o mundo dos assuntos humanos é o campo da liberdade política em que o ator tem a oportunidade de individualizar-se, de manifestar sua singularidade, por meio de palavras e ações distintas" (BOWEN-MOORE, 1989, p. 48).

${ }^{3}$ Em sua tese de doutorado, Arendt discute a natalidade em contraposição a mortalidade, "teme-se a morte porque se ama o mundo (amor mundi) [...] a morte destrói a relação natural no mundo da qual o amor mundi é a expressão" (ARENDT, 1997, p. 95). A natalidade é vista como resposta a condição humana da mortalidade, relação que Arendt discutira também na obra A condição humana (1958), que inicialmente Arendt pensou em intitular de Amor mundi.
} 
Civitate Dei $^{4}$-, que Hannah Arendt retornou à ideia de natalidade, apresentando-a em um sentido estritamente político. Escreve Arendt,

O começo, antes de tornar-se evento histórico, é a suprema capacidade do homem; politicamente, equivale à liberdade do homem. Initium ut esset homo creatus est - "o homem foi criado para que houvesse um começo", disse Santo Agostinho. Cada novo nascimento garante esse começo; ele é, na verdade, cada um de nós. (ARENDT, 1989, p. 531)

Na passagem citada por Arendt, Santo Agostinho afirma que o homem foi criado para que houvesse um começo; certamente a interpretação de Arendt, vinculando a afirmação agostiniana ao contexto da liberdade política, não condiz com as intenções de Agostinho, que procurou interpretar a liberdade inclinada para o âmbito da vontade e não para a esfera da liberdade política. Contudo, Agostinho não é a única referência de Arendt no que concerne à categoria da natalidade política. Para Arendt, Virgílio foi certamente o primeiro a associar natalidade e política, tendo legado tal visão ao pensamento agostiniano, quando em seu poema Écloga, o autor professa "um hino a natividade, um louvor ao nascimento de uma criança e o anúncio de uma nova geração" (ARENDT, 2011, p. 270). Por essa razão, estamos de acordo com Hammer quando afirma que Virgílio representa para Arendt “a expressão política romana da forma mais pura" (2002, p. 131), fornecendo, assim, uma forma de pensamento político puro, baseado na fundação e nas experiências da ação política no mundo.

Por ora, deixemos de lado o diálogo entre as intenções de Arendt e Agostinho e a influência de Virgílio sobre o conceito agostiniano de natalidade, e voltemos ao propósito de nosso texto, isto é, ao objetivo de perceber algumas das principais nuances do conceito de natalidade, recorrente em quase todas a obras de Arendt e central na compreensão de seu pensamento político, bem como à compreensão do novus ardo saeclorum das revoluções modernas e contemporâneas. Em um primeiro momento, é importante demarcar que pensar a natalidade política para Arendt é pensar também a fragilidade das instituições humanas e a possibilidade sempre real do aparecimento de novas instituições, que se atualizam por meio da capacidade

\footnotetext{
${ }^{4}$ A citação não corresponde ao capítulo XX do livro XII, conforme referenciada por Hannah Arendt em Origens do Totalitarismo e n'A condição humana, mas ao capítulo XXI do mesmo livro, em que Santo Agostinho afirma "quod initium e o modo antea numquam fuit. Hoc ergo ut esset, creatus est homo, ante quem nullus fuit" (De Civitate Dei, XII, 21).
} 
humana de iniciar coisas novas no mundo, como fizeram os homens das duas principais revoluções modernas.

Para fins de contextualização, é importante frisarmos também que a interpretação política da natalidade, conforme proposta por nossa autora, foi desenvolvida inicialmente na obra A condição humana (1958), na qual Arendt avulta mais especificamente a ideia de natalidade humana, uma vez que, para a autora, “a condição da ação é a natalidade” (ARENDT, 2006, p. 662), manifesta pelo milagre dos novos $\operatorname{começos}^{5}$. Segundo Canovan, a ideia de natalidade expressa por Arendt transmite ao mundo uma mensagem de fé e esperança6, possível porque "novas pessoas estão continuamente chegando ao mundo, cada uma delas única e capaz de novas iniciativas" (2016, p. LXIV). Assim, os "recém-chegados" trazem consigo a esperança da natalidade, entendida como segundo nascimento e a marca da novidade impressa por meio da ação, sendo capazes de realizar, por amor ao mundo, o surpreendente milagre dos novos começos; logo, "a natalidade é uma possibilidade sempre presente de atualizarmos, por meio da ação, a singularidade da qual o nascimento de cada indivíduo é uma promessa" (CORREIA, 2010, p. 813).

Em outras palavras, os recém-chegados ao mundo se identificam pelo fato de que suas “ações e reações não podem ser previstas por aqueles que nele já se encontram" (ARENDT, 2007, p. 92-93), sendo marcados pelo signo da novidade, suas ações, assim como todas as ações livres, carregam consigo a marca da imprevisibilidade, que só aparece e se revela por completo depois que a ação termina. Essa ação, que é própria da natalidade humana, representa a novidade no mundo dos assuntos humanos, e "só se revela plenamente para o contador de história [storyteller], ou seja, para o olhar retrospectivo do historiador, que realmente sempre sabe melhor o que aconteceu do que os participantes" (ARENDT, 2016, p. 238). Foi assim que os homens das duas revoluções modernas só foram capazes de perceber o páthos da novidade no decurso

\footnotetext{
${ }^{5}$ Nas palavras de Hannah Arendt, "o novo sempre acontece em oposição à esmagadora possibilidade das leis estatísticas e à sua probabilidade que, para todos os fins práticos e cotidianos, equivale à certeza; assim, o novo sempre aparece na forma de um milagre" (ARENDT, 2016, p. 220).

${ }^{6}$ Na mesma direção de Canovan, Rosa afirma que para Arendt, "a natalidade é o mundo humano em contínuo estado de revelação. A vida nascente é o acúmen e a essência fenomenológica de toda manifestação. Por outras palavras, é o nascimento de novos seres humanos e o novo começo, a acção de que são capazes por terem nascido". (ROSA, 2006, p. 129).
} 
das revoluções, sendo surpreendidos "quando a novidade chegou à praça pública, [...] iniciada - embora inadvertidamente - por homens em ação" (ARENDT, 2011, p. 78).

Embora alguns intérpretes do pensamento arendtiano defendam que existe uma tensão entre o conceito de ação presente nas obras The human condition e On Revolution ${ }^{7}$, não estamos seguros de que tal tensão possa, de fato, se efetivar ou ser determinante na compreensão do conceito arendtiano de ação, uma vez que nas duas obras mencionadas a categoria da ação está vinculada diretamente à ideia de natalidade política e liberdade política e, conforme assevera Duarte (2000, p. 214), tanto a ação quando a liberdade estão "radicadas ontologicamente na 'natalidade' humana"; assim sendo, o conceito de natalidade se constitui, em nosso entendimento, como uma categoria chave para a compreensão da teoria arendtiana da ação e para o entendimento do fenômeno revolucionário. Defendemos, ainda, que o conceito de natalidade política expressa, sobretudo, o páthos da novidade presente nas duas revoluções modernas, isto é, “o páthos revolucionário de um início totalmente novo [que] nascia apenas no decorrer do próprio acontecimento" (ARENDT, 2011, p. 66). É nesse sentido que o conceito de novo início nas obras de Arendt remete à experiência concreta das revoluções modernas ${ }^{8}$, pois foram os homens dessas revoluções que tornaram possível a experiência da novidade no âmbito da política moderna à medida que se tornaram iniciadores, que revelaram o seu "quem" por meio da

\footnotetext{
${ }^{7}$ Dentre os autores que defendem a existência de uma tensão na teoria arendtiana da ação, podemos citar Passarim D'Entreves e Seyla Benhabib. D'Entreves defende que a teoria da ação de Arendt só pode ser explicada se tivermos como pano de fundo "a tensão fundamental existente em sua teoria entre um modelo expressivo e um modelo comunicativo da ação" (D’ENTREVES, 1994, p. 84). De acordo com D’Entreves, essa tensão afeta não só a conceituação de ação presente na obra arendtiana, mas toda a sua visão de política. 0 autor defende, não explicitamente, que existe uma divisão epistemológica na teoria da ação de Arendt, que corresponde aos escritos anteriores e presentes na obra A condição humana, onde predomina um modelo expressivo da ação; e, por outro lado, defende que os escritos voltados para sua reflexão sobre as revoluções correspondem a outra leitura da ação, onde prevalece um modelo comunicativo da ação. Seyla Benhabib, em sua obra The reluctante modernism of Hannah Arendt, ao discutir sobre a teoria da ação arendtiana, recorre ao par constituído pelos modelos agonal e narrativo da ação, presentes nos escritos de Arendt, para a autora "a ação em um modelo agonal é descrito através de termos como 'revelação do quem alguém é' e 'torna manifesto o que é interior, a ação no modelo narrativo é caracterizado através do 'contador de história' e do 'tecedor de uma rede de narrativas' (BENHABIB, 2003, p. 125). Portanto, ambos, Passarim D’Entreves e Seyla Benhabib, bem como outros autores aqui não mencionados, defendem, cada uma a seu modo, a existência de uma tensão presente na teoria da ação de Hannah Arendt.

${ }^{8}$ Nessa direção, concordamos com Rubiano ao defender que para Arendt, "a fundação de algo que nunca existiu e o início de uma nova época só foram formulados enquanto experiência a partir das revoluções modernas" (RUBIANO, 2016, p. 84). É, portanto, apenas a partir dessa experiência concreta que podemos falar do páthos da novidade, isto é, do milagre do novo início.
} 
"capacidade de iniciar [que] se radica na natalidade, no fato de que os seres humanos aparecem no mundo em virtude do nascimento" (ARENDT, 2011, p. 270). Dessa feita, podemos afirmar, em resumo, que as experiências da natalidade, ação política, liberdade e revolução são essenciais para se pensar o fenômeno político moderno a partir do prisma arendtiano.

Aqui, convém que possamos explanar um pouco mais sobre o problema do início, ou nas palavras de Etienne Tassin, da aporia do início, teorizada por Arendt em suas obras. Conforme Arendt explica, os gregos tinham duas palavras para designar o agir, “arkhein: começar, conduzir e, por último, governar; e práttein: levar a cabo alguma coisa" (2007, p. 214). Etienne Tassin (2016, p. 112) esclarece ainda que "agir é iniciar, mas iniciar não é comandar [...] a ação inicia, mas este início não garante que o que ele inicia prosseguirá e se efetivará”. As revoluções modernas vivenciaram, cada uma a seu modo, o problema do início ou da natalidade, e tiveram, portanto, que enfrentar essa dupla aporia do início, ora enquanto começo (arkhein), ora como realização (prattein). Tal problema, segundo Arendt, já havia sido tomado por Platão que "instaura um abismo entre os dois modos de ação, archein e prattein ("começar" e "realizar"), que, para os gregos, eram interconectados" (ARENDT, 2016, p. 275).

De acordo com Tassin, para pensarmos a ação a partir da categoria do início, não podemos desconsiderar duas armadilhas do pensamento que surgem dessa relação entre os verbos arkhein e prattein. A primeira "vem dissociar, como fez Platão, as duas dimensões do início (arkhein) e da realização (prattein) [...] e assegurar que o ato de comandar, que inicia, se subordina ao ato de executar, que cumpre a tarefa" (2016, p. 114). Nessa primeira armadilha, a ação perde aquilo que lhe é próprio, isto é, a capacidade de iniciar algo novo, tendo como propósito apenas a garantia de sua efetivação. Por sua vez, a segunda armadilha decorre da tentativa de agrupar, na ideia de início, o princípio de sua liberação, assim, "o que inicia contém em si, de partida, seu telos que o guia até o fim" (2016, p. 114). Logo, arkhein poderia significar, ao mesmo tempo, início e comando, e a ação perderia, então, sua condição de indeterminação.

Dessas duas armadilhas, podemos concluir, sendo fiéis às considerações de Tassin, que o início e a ação enquanto início, tal como se manifestou no contexto das revoluções modernas, reclamam uma nova interpretação ou mesmo a distinção dos termos arkheim e prattein, isso porque a ação revolucionária nos coloca diante do seguinte problema: “como pensar uma ação 
cujo princípio é iniciar, mas iniciar sem princípio, sem príncipe nem autoridade?" (TASSIN, 2016, p. 115).

No que se refere à ação revolucionária, Tassin considera que ela é dupla:

Ela derruba o antigo regime e instaura uma nova ordem, ou seja, libera do antigo julgo e funda um espaço de liberdade: libertação e fundação. Mas ela se encontra confrontada com três problemas: uma violência inevitável, uma autoridade incapaz e um futuro indeterminável. (TASSIN, 2016, p. 115)

Assim, para Arendt, a violência enquanto fenômeno marginal sempre impossibilita o aparecimento da ação e da liberdade política e, embora seja necessária e parte do processo revolucionário, precisa cessar para que a ação política possa aparecer. Logo, é importante frisar que as revoluções, apesar de terem feito uso da violência, sempre tiveram seus objetivos atrelados à causa da liberdade. Quanto ao tema da autoridade, esse está diretamente relacionado com a tradição e com o advento das revoluções. O conceito de autoridade política e a perda da autoridade ocorrida na modernidade são indispensáveis à compreensão do fenômeno revolucionário e ao conceito de natalidade enquanto categoria que torna possível a experiência dos novos inícios.

Contudo, aqui nos interessa discutir brevemente sobre a categoria do início enquanto correlata ao princípio, e sua condição de arbitrariedade, "que surge do nada e não indica nenhuma direção determinada" (TASSIN, 2016, p. 115). De acordo com Arendt, “o início e o princípio, não só estão relacionados entre si, mas são simultâneos [...] o princípio inspira os atos que se seguirão e continua a aparecer enquanto dura a ação" (2011, p. 272); assim, é impossível pensar o início dissociado do princípio, pois ambos aparecem juntos no mundo, sendo o princípio, segundo Arendt, o absoluto do qual o início retira sua validade ${ }^{9}$. No entanto, é preciso compreender que o princípio não comanda a ação, preservando assim sua condição de imprevisibilidade, o princípio apenas "inspira os atores deixando claro para eles o sentido de suas ações" (TASSIN, 2016, p. 117).

\footnotetext{
${ }^{9}$ Arendt explica que os homens das revoluções eram sempre levados a buscar um absoluto, isso justifica-se talvez por meio dos "velhos hábitos intelectuais dos homens do Ocidente, segundo os quais cada início inteiramente novo precisa de um absoluto do qual tenha brotado e pelo qual seja 'explicado'” (ARENDT, 2011, p. 265).
} 
A experiência da natalidade política vivida pelos homens das revoluções enquanto fenômeno inteiramente novo, revela o aparecimento do início enquanto princípio de toda ação que, rompendo com os ciclos da história, promove a experiência do recomeço, pois, segundo Tassin, “todo início que não visasse a instauração de possíveis (re)inícios contraria seu princípio e condenaria a revolução ao fracasso" (2016, p. 118). Com isso, a aporia do início ou do começo presente no pensamento de Arendt tem por propósito preservar a redescoberta da ação e da liberdade política diante das inúmeras tentativas modernas de eliminação da ação, ou de redução da mesma a uma dimensão meramente teleológica. Com a preservação dos espaços de liberdade e ação, os recém-chegados ao mundo têm a certeza de um lugar garantido para experimentar as potencialidades de começar algo novo no mundo e o espaço da política fica protegido da zona do esquecimento que põe em risco sua permanência (cf. BOWEN-MOORE, 1989, p. 56).

Logo, se as revoluções modernas são, para Arendt, o signo da natalidade política, isso se dá pelo fato de elas terem surgido de maneira completamente inesperada, de terem criado espaços de liberdade política e incentivado o estabelecimento de instituições republicanas e duradouras nas quais a liberdade pudesse aparecer e ser preservada. Assim, Arendt defende que mesmo os levantes revolucionários que não obtiveram sucesso são importantes, porque deixaram para o mundo a marca de sua grandeza, manifestada pela capacidade humana de agir em conjunto e de dar início a novos começos. Se Arendt dá ênfase à Revolução Americana, pondoa em uma condição privilegiada diante da Revolução Francesa, isso se deve principalmente ao mérito dos americanos de terem conseguindo estabelecer um novus ardo saeclorum, a república, que “nasceu não por 'necessidade histórica' nem por um desenvolvimento orgânico, e sim por um ato deliberado: a fundação da liberdade" (ARENDT, 2011, p. 276).

Portanto, nos termos de Arendt, as revoluções modernas, enquanto acontecimento político único, revelam o momento em que os homens, sentindo-se capacitados para a tarefa de iniciar, aparecem para o mundo por meio de um segundo nascimento, um nascimento propriamente político, que se radica na natalidade e na capacidade de ação conjunta no espaço de pluralidade humana. Assim, em linhas gerais, as revoluções significam, "os únicos eventos políticos que nos colocam diante do problema dos inícios de uma maneira frontal e inescapável” (ARENDT, 2011, p. 47). 


\section{Considerações finais}

Analisar o conceito de natalidade em Arendt é, sobretudo, se debruçar sobre uma das principais categorias de sua teoria política, pois é "a natalidade, e não a mortalidade, [...] a categoria central do pensamento político" (ARENDT, 2016, p. 11). A natalidade (natality) significa, conforme discutimos, a capacidade que temos de iniciar coisas novas em um mundo já existente, sendo, portanto, uma espécie de segundo nascimento, no qual nascemos por meio de nossas ações e da imprevisibilidade que é própria dessas mesmas ações. Assim, ação e natalidade mantêm entre si uma relação estreita, sendo a base de todas as atividades humanas e mais especificamente de nossas atividades políticas.

Nesse sentido, defendemos neste artigo a hipótese de que a categoria política da natalidade humana e a análise arendtiana das revoluções modernas precisam ser tomadas simultaneamente, pois o novus ardo saeclorum que motivou os homens das revoluções, despertando neles o desejo de iniciar e de fundar uma nova República, tem como signo a faculdade da ação que, segundo Arendt, se radica ontologicamente na natalidade humana. De modo geral, natalidade e revoluções, assim como ação política e liberdade, precisam ser pensadas conjuntamente enquanto categorias e eventos centrais para se compreender a política, bem como suas principais manifestações na modernidade.

Por fim, acreditamos que esses são apenas alguns elementos dentre tantos outros que nos permitem buscar compreender a importância da categoria política da natalidade e sua relação com o fenômeno revolucionário moderno à luz do pensamento político de Hannah Arendt.

\section{Referências}

ARENDT, H. A condição humana. Trad. R. Raposo; revisão técnica A. Correia. 13. Ed. Rio de Janeiro: Forense Universitária, 2016.

ARENDT, H. Diario Filosófico 1950-1973. Trad. R. Gabás. Barcelona: Herder, 2006.

ARENDT, H. Entre o Passado e o Futuro. Trad. M. W. Barbosa. São Paulo: Perspectiva, 2007a.

ARENDT, H. Origens do Totalitarismo. Trad. R. Raposo. São Paulo: Companhia das Letras, 1989.

ARENDT, H. 0 conceito de amor em Santo Agostinho. Trad. A. P. Dinis. Lisboa: Instituto Piaget, 1997.

ARENDT, H. Sobre à Revolução. Trad. D. Bottmann. São Paulo: Companhia das Letras, 2011. 
AGOSTINHO. De Civitate Dei. In: The Latin Library. Disponível em: https://www.thelatinlibrary.com/augustine/civ21.shtml. Acesso em: 10 jul. 2021.

BENHABIB, S. The reluctant modernism of Hannah Arendt. Lanham: Rowman \& Littlefield Publishers, 2003.

BOWEN-MOORE, P. Hannah Arendt's Philosophy of Natality. London: Palgrave Macmillan UK, 1989.

CANOVAN, M. Introdução. In: ARENDT, H. A condição humana. Trad. R. Raposo; revisão técnica A. Correia. 13. Ed. Rio de Janeiro: Forense Universitária, 2016.

CORREIA, A. Natalidade e amor mundi: sobre a relação entre educação e política em Hannah Arendt. Educação e Pesquisa, São Paulo, v. 36, n. 3, p. 811-822, set./dez. 2010.

D’ENTRÈVES, M. The political philosophy of Hannah Arendt. Londres/Nova York: Routledge, 1994.

DUARTE, A. 0 pensamento à sombra da ruptura: política e filosofia em Hannah Arendt. São Paulo: Paz e Terra, 2000.

HAMMER, D. Hannah Arendt and roman political thought: the practice of theory. Political Theory, v. 30, n. 1, pp. 124-149, feb., 2002.

ROSA, J. M. 0 milagroso poder de começar. Hannah Arendt leitora de Santo Agostinho. Mediaevalia: textos e estudos, n. 25, p. 105-129, 2006.

RUBIANO, M. Revolução em Hannah Arendt: compreensão e história. 2016. 280 f. Tese (Programa de Pós-Graduação em Filosofia). Departamento de Filosofia, Universidade de São Paulo, São Paulo, 2016.

TASSIN, E. Como continuar o que inicia: a tripla aporia revolucionária. Cadernos de Filosofia Alemã, v. 21, n. 3, pp. 111-122, 2016.

Recebido em: 10/12/2021

Aprovado em: 21/12/2021

\section{Antônio Batista Fernandes}

Doutorando em Filosofia pela Universidade Federal do Ceará (UFC). Mestre em Filosofia pela Universidade Federal do Ceará (UFC). Especialista em Docência do Ensino Superior pelo Centro Universitário Católica de Quixadá. Bacharel em Filosofia pelo Instituto Filosófico-Teológico N. Sra. Rainha do Sertão de Quixadá/CE. Licenciado em Filosofia pela Faculdade Evangélica do Meio Norte (FAEME/MA). Editor da Revista Dialogando: Revista Interdisciplinar de Filosofia e Teologia. Docente do Centro Universitário Católica de Quixadá (UNICATÓLICA de Quixadá). Atua desenvolvendo pesquisas nas áreas de Filosofia Política, Ética e Republicanismo, com ênfase no pensamento de Hannah Arendt. 